\title{
Riscos ocupacionais de uma indústria calçadista sob a ótica dos trabalhadores
}

\author{
Occupational risks of a shoe industry from the workers' perspective \\ Riesgos laborales de una industria de calzado en la visión de los trabajadores
}

\section{Fernanda Reinher da Luz', Marli Maria Loro", Regina Célia Gollner Zeitoune"II, Adriane Cristina Bernat Kolankiewicz", Cleci Schmidt Piovesan Rosanelli"}

' Universidade Regional do Noroeste do Estado do Rio Grande do Sul, Curso de Enfermagem (Graduanda). Ijuí-RS, Brasil. "Universidade Federal de São Paulo, Curso de Pós-Graduação em Enfermagem (Doutoranda). São Paulo-SP, Brasil.

II' Universidade Federal do Rio de Janeiro, Escola de Enfermagem Anna Nery,

Departamento de Enfermagem de Saúde Pública. Rio de Janeiro-RJ, Brasil.

Submissão: 31-03-2011 Aprovação: 06-02-2013

\section{RESUMO}

O estudo teve como objetivo identificar os riscos ocupacionais de uma indústria calçadista sob a ótica dos trabalhadores, bem como as medidas preventivas adotadas por eles contra os riscos. Realizou-se um estudo qualitativo, descritivo. A amostra foi composta por quinze trabalhadores. Os dados foram coletados por entrevista semiestruturada e analisados à luz da análise de conteúdo. Foram respeitados os aspectos éticos e a pesquisa foi aprovada pelo Comitê de Ética em Pesquisa da Universidade Regional do Noroeste do Estado do Rio Grande do Sul. Os resultados apontam que os trabalhadores são conhecedores dos riscos do seu processo de trabalho, faziam uso de medidas de proteção individual e a empresa disponibilizava dispositivos de segurança, informando e realizando, periodicamente, visitas aos setores, na perspectiva de desenvolver ações educativas.

Descritores: Riscos Ocupacionais; Prevenção de Acidentes; Equipamento de Proteção.

ABSTRACT

This is a qualitative and descriptive study, which aimed to identify the occupational risks of a shoe industry, as well as the preventive measures taken against those risks, from the workers' perspective. The sample consisted of fifteen workers. Data were collected through semi-structured interviews and analyzed according to content analysis. The ethical aspects were respected and the research was approved by the Committee of Ethics in Research of the Northwest Regional University of Rio Grande do Sul. The results showed that the workers are aware of the risks of their work process, made use of safety measures for personal protection, and the company offers safety devices, informing and performing periodical visits to the sectors, aiming to develop educational actions.

Key words: Occupational Risks; Accident Prevention; Protection Equipments.

\section{RESUMEN}

Estudio cualitativo descriptivo, que tuve como objetivo identificar los riesgos laborales de una industria de calzado, así como las medidas preventivas adoptadas frente a los riesgos, en la visión de los trabajadores. La muestra fue compuesta por quince trabajadores y los datos fueran obtenidos por entrevista semi-estructurada y analizados a luz de la analísis de contenido. Los aspectos éticos fueran respetados y la investigación fue aprobada por el Comité de Ética en Pesquisa de la Universidad Regional del Estado de Rio Grande do Sul. Los resultados apuntaran que los trabajadores conocen los riesgos de su proceso de trabajo, hacen uso de medidas de protección personal, y que la empresa proporciona dispositivos de seguridad, informando y realizando visitas periódicas a los sectores con el fin de desarrollar actividades educativas.

Palabras clave: Riesgos Laborales; Prevención de Accidentes; Equipo de Protección.

\section{AUTOR CORRESPONDENTEＭarli Maria LoroＥ-mail: marlil@unijui.edu.br}




\section{INTRODUÇÃO}

No Brasil a indústria de calçados é um importante setor da economia, tendo em vista o volume de produção, sua parcela expressiva de exportação e capacidade de geração de empregos $^{(1)}$. No entanto, constitui-se em um espaço em que os riscos ocupacionais são uma constante, sendo inerentes ao processo de trabalho. Pesquisa direcionada a estes ambientes evidencia que a exposição aos diferentes riscos ocupacionais é inevitável em virtude do crescimento da industrialização no mundo. Isso fez com que, a partir da segunda metade do século passado, estudos fossem realizados nessa área, os quais possibilitaram relacionar riscos do processo de trabalho a efeitos adversos à saúde, justificando a necessidade de se adotar medidas preventivas adequadas, com vistas a minimizar possibilidades de agravos à saúde dos envolvidos ${ }^{(2)}$.

Essa indústria absorve uma significativa força produtiva detentora de conhecimentos, habilidades e destrezas manuais imprescindíveis à produção. Esse processo envolve diversas etapas na busca por agilizar a atividade, melhorar a qualidade dos produtos e, em consequência, aumentar a produtividade.

Nesse contexto, o trabalho representa para o homem uma necessidade básica de sobrevivência. Também, por meio dele é que o homem em uma sociedade capitalista melhor desenvolve suas aptidões, sejam elas: físicas, intelectuais ou morais. Varias transformações ocorreram nas ultimas décadas, envolvendo relações complexas entre o homem, a sociedade e o processo de produção ${ }^{(2)}$.

Na sociedade contemporânea, ocorrem mudanças, as quais se manifestam em modos de desenvolver as atividades ocupacionais diferentes em sua natureza, ritmo e formas. Assim, se redefinem as subjetividades e os sujeitos ${ }^{(3)}$. Nesse processo, novas tecnologias foram implementadas o que, por vezes, pode resultar na exposição do trabalhador a maiores, ou mesmo, aos novos riscos ambientais, inerentes ao processo de produção da indústria calçadista(4).

Risco ambiental é definido como qualquer possibilidade de que algum elemento ou situação quando presentes no ambiente laboral ou mesmo no processo de trabalho possam causar dano à saúde seja por doença, acidente ou mesmo por sofrimento ao trabalhador, ou ainda poluição ambiental(5). Estes, algumas vezes, ocorrem de maneira abrupta e outras de forma insidiosa, o que pode comprometer à integridade física e mental, bem como com repercussões pessoais e sociais expressivas ${ }^{(6)}$.

Ainda, o Ministério do Trabalho e Emprego, em suas normas regulamentadoras, aponta que o risco ambiental advém de agentes físicos, químicos e biológicos existentes no ambiente de trabalho que, dependendo da sua natureza, concentração ou intensidade e tempo de exposição, são capazes de causar danos à saúde dos envolvidos ${ }^{(7)}$.

Nesse contexto, o processo saúde e adoecimento resulta da interação dinâmica das condições de vida, das relações e do processo laboral, bem como do seu controle com vistas a interferir nas suas condições de trabalho e de vida. Nesse âmbito, é essencial que o homem se aproprie de conhecimento e informação acerca dos riscos na tentativa de minimizar a sua exposição. Assim, faz-se necessário que se identifique aqueles oriundos do ambiente de trabalho e, também possam reconhecer e adotar medidas de prevenção, bem como propor alternativas para a promoção de sua saúde e integridade física.

Para tanto, faz-se necessário dar ênfase das ações educativas em saúde no ambiente ocupacional, uma vez que, neste campo de atuação é possível reconhecer as situações causadoras de risco/perigo, por meio de ações de higiene do trabalho, bem como suas repercussões para a vida do individuo. Assim, faz-se necessário que os trabalhadores assumam a condição de sujeitos como sendo prioritária para a manutenção de sua saúde.

Aprofundar estudos no que tange aos diferentes riscos a que os trabalhadores estão expostos justifica-se, pois, quando o sujeito é conhecedor das situações que podem resultar em acidentes e agravos para sua saúde e integridade física tem possibilidade de implementar ações preventivas.

Nessa perspectiva, a investigação teve como objetivo identificar os riscos ocupacionais de uma indústria calçadista sob a ótica dos trabalhadores, bem como as medidas preventivas contra os riscos adotadas por eles.

\section{METODOLOGIA}

Estudo de natureza qualitativa, descritiva, realizado junto à indústria calçadista de um município do Noroeste do Estado do Rio Grande do Sul. Os critérios de inclusão dos sujeitos foram: ser trabalhador da empresa; maior de 18 anos e desenvolver atividades laborais por no mínimo seis meses na referida empresa.

Por ser uma investigação de natureza qualitativa utilizou-se o critério de exaustão o que resultou em uma população de 15 trabalhadores, com idade entre 19 e 44 anos, sendo nove do sexo feminino e seis do masculino, com tempo de trabaIho, na indústria, de um a três anos. Em relação aos setor em que desempenham suas atividades, nove estavam no de costura, dois no de corte, dois no almoxarifado, um no setor de recursos humanos e um no setor de expedição e exportação.

A obtenção das informações deu-se por meio de entrevista semiestruturada, realizada nos meses de outubro e novembro 2010. Foram realizadas em uma indústria calçadista localizada na região noroeste do Estado do Rio Grande do Sul/Brasil em uma sala reservada com o intuito de preservar a privacidade dos entrevistados, com tempo médio de 30 minutos, gravadas em audiotape, transcritas na integra e, posteriormente, analisadas. Visando manter o anonimato dos participantes optou-se por identificá-los pela letra $\mathrm{E}$, seguida do número da ordem de realização da entrevista, ou seja, E1 a E15. Para testar a consistência do instrumento, foi realizado um teste, com vistas a verificar a necessidade de adequação do instrumento, com dois trabalhadores, os quais não integraram, posteriormente, a população do estudo.

O estudo foi avaliado pelo Comitê de Ética em Pesquisa da Universidade Regional do Noroeste do Estado do Rio Grande do Sul - UNIJUI, aprovado, mediante Parecer no 251/2010. A análise das informações deu-se por meio da organização, leitura, releitura, classificação e análise, de acordo com as diretrizes da análise de conteúdo ${ }^{(8)}$, resultando em dois temas: Percepção de risco ocupacional sob a ótica do trabalhador; 
Medidas de segurança adotadas na perspectiva de minimizar os riscos ocupacionais.

\section{ANÁLISE E DISCUSSÃO DOS RESULTADOS}

O homem moderno encontra dificuldade em dar sentido à vida senão pelo trabalho. No entanto, o ambiente laboral, pode representar risco para a saúde dos envolvidos no processo. Nesse contexto, as condições em que o processo de trabalho estabelece-se são fundamentais para que ocorra uma relação harmoniosa entre saúde e a atividade desenvolvida. Isso decorre em função de que o mundo contemporâneo está cada vez mais complexo e, manter o bem-estar físico, psicológico e social, pode ser uma tarefa desafiadora.

Assim, torna-se imperativo que as empresas realizem esforços no sentido de manter a saúde dos seus trabalhadores. Para tanto, o ambiente laboral, necessita ser avaliado quanto às condições insalubres que podem advir do processo de trabalho, uma vez que, tais condições têm potencial de oferecer risco à saúde.

\section{A. Percepção de risco ocupacional sob a ótica do trabalhador}

Em relação aos riscos ocupacionais, importante destacar que cada categoria profissional tem, em seus processos, as peculiaridades do trabalho e formas de organização e divisão do trabalho os expõem, uma vez que, permanecem nesse ambiente, durante toda a jornada laboral e grande parte da vida produtiva $^{(2)}$.

No caso dos sujeitos do estudo em foco a situação não é diferente, pois eles identificavam riscos intrínsecos ao seu processo de trabalho e destacaram a possibilidade do contato com máquinas podendo comprometer sua integridade física.

\section{Perigo de cortar o dedo, furar com agulhas. (E 1)}

De esmagar os dedos, máquinas de dividir, de colar contraforte, máquina de chanfrar a gente corre o risco de chanfrar os dedos, pois tem uma navalha afiada. Na máquina de costura pode furar com a agulha nos dedos, temos que ter cuidado, mas mesmo assim, por vezes nos machucamos. (E 3)

Em algumas máquinas tem risco, como chanfradeira, navaIha afiada, máquina de costura, escova, monta bico, cola quente nas máquinas internacionais. (E 9)

Da mesma forma, pesquisa realizada na região sudoeste da Bahia, em um pólo calçadista, revela que a organização, os processos e as relações sociais de produção podem apresentar aspectos que afetam a saúde física e psicológica impactando, negativamente, na qualidade de vida dos indivíduos vinculados à produção. Amputações de membros são um dos principais problemas físicos que acometem o ramo calçadista no sudoeste baiano $^{(9)}$.

Neste contexto, os acidentes de trabalho (AT) ocupam destaque, uma vez que, se constituem em agravos à saúde em decorrência da atividade laboral, recebendo interferências de variáveis inerentes à própria pessoa, do ponto de vista físico ou psíquico, bem como do contexto social, econômico, político e da própria existência. Eles resultam da ruptura da relação entre homem e processo de trabalho e interferem no processo saúde/doença contribuem para a ocorrência de doenças ${ }^{(10)}$.

Importante elucidar que o processo de produção do calçado de couro, envolve operações que estão organizadas em cinco etapas: modelagem, corte, costura, que pode ser manual ou à máquina, montagem e acabamento. $\mathrm{O}$ número de operações realizadas em cada uma dessas etapas varia de acordo com o modelo de calçado a ser produzido, o tipo de organização adotada, a tecnologia empregada e o porte da empresa ${ }^{(2)}$.

Diante dos riscos a que os trabalhadores estão expostos no seu cotidiano, salienta-se a importância dos mesmos manterem-se atento a toda atividade que desenvolvem na perspectiva de evitar agravos, os quais podem ser mutilantes.

Tem risco de prensar os dedos nas maquinas se você não cuidar e, em nosso trabalho tem que prestar atenção para não colocar a mão na maquina. (E12)

Risco de prensar os dedos, máquina de, chanfrar o dedo na navalha, pois ele é muito afiado, de passar cola. (E11)

Estudo aponta que trabalhadores da indústria calçadista, frequentemente, sofrem mutilações de dedos, mãos e parte dos membros superior em decorrência da atividade ocupacional, o que demonstra a gravidade e a necessidade de reestruturação produtiva(2).

No que se refere à origem dos riscos ocupacionais estes advêm das atividades insalubres e perigosas, aquelas cuja natureza, condições e métodos de trabalho, bem como os mecanismos de controle sobre os agentes biológicos, químicos, físicos e mecânicos podem provocar efeitos adversos à saúde dos profissionais ${ }^{(10)}$.

A legislação brasileira conceitua AT como os eventos ocorridos pelo exercício do trabalho a serviço da empresa, que causem lesão corporal ou perturbação funcional, morte, perda ou redução da capacidade para o trabalho(7).

Cabe destacar, que sempre que ocorre um acidente, desencadeia-se um desequilíbrio no processo de trabalho, para tanto, não pode ser considerado como algo natural e inerente ao processo. Paralelo a isso, estudos apontam que o AT e visto como natural e se interliga a sociedade que se industrializa e que toda a atividade profissional possui certa periculosidade o que expõe a sujeito a agravos a sua saúde ${ }^{(2)}$.

Ainda empiricamente observa-se no cotidiano de alguns profissionais, certo desconhecimento em relação ao seu fazer profissional e sua relação com o processo saúde/doença. No entanto, denota-se nas alocuções dos sujeitos que estes são conhecedores dos riscos e da necessidade da constante atenção no desempenho de suas atividades a fim de evitar, ao máximo, a ocorrência de acidentes.

Em máquina de costura, forno, prensa, na internacional... Sei que em cada uma delas tem o seu risco... que pode ocorrer um acidente. (E6) 
Isso é tudo conforme a gente trabalha... Tudo tem risco, ainda mais na máquina... Se você não ficar atento você sempre está correndo risco. Temos que cuidar sempre, pode saltar um prego... eu tenho óculos de proteção, que é muito necessário. (E13)

A falta de atenção tem sido a principal causa de AT. Importante mencionar, que este fato somado a resistência do profissional em utilizar os dispositivos de segurança, bem como seu uso incorreto aumenta, consideravelmente, a exposição e possibilidade de acidentes ${ }^{(11)}$.

O não cumprimento das normas de trabalho pelos funcionários, não usar proteção, falta de atenção podem gerar acidentes. (E15)

Não estar atento nas normas e no trabalho... Pode acontecer acidente. (E02)

Técnicos, especialistas em saúde do trabalhador inferem que o essencial não é gratificar o servidor com adicional de insalubridade ou de periculosidade, mas que o empregador necessita programar ações que tornem insalubres o trabalhador e o ambiente laboral. Para tanto, as empresas devem implementar programas que contemplem normas de segurança e higiene de trabalho, entre elas tornar obrigatório o uso de dispositivos de segurança no exercício profissional em atividades com potencial de comprometer a saúde e integridade física.

Temos que fazer uso de protetores, cuidar com a poeira, usar calçados fechados, perigo de cair tesoura, cabelo preso sempre, pois tem risco de enroscar nas máquinas. (E1)

Depende do trabalho que está fazendo... Sempre na máquina de refilar tem que ter cuidado, tem que ter proteção na máquina de dividir... Tem as medidas de segurança como fazer uso de cremes nas mãos, calçado fechado, cabelo amarrado, protetor de ouvido que são usadas sempre, mas mesmo assim ainda ocorrem acidentes. (E7)

Faz-se necessário concentrar esforços e recursos na perspectiva de mudanças no ambiente ocupacional como implementação de programas de prevenção, conscientização de práticas seguras e o fornecimento dos dispositivos de segurança, de forma contínua, uniforme e gratuita ${ }^{(11)}$. Cabe destacar que a legislação trabalhista prevê a disponibilização, quando necessário, de Equipamentos de Proteção Individual (EPI) de forma imediata e gratuita ${ }^{(7)}$.

Outro risco identificado pelos depoentes é o ergonômico e o relacionam ao ambiente laboral da indústria. O risco ergonômico relaciona-se a não adaptação das condições de trabalho às características psicofisiológicas dos trabalhadores ${ }^{(7)}$. Isto ocorre quando há disfunção entre os indivíduos e seus equipamentos de trabalho, como esforço físico intenso, repetitividade, postura inadequada, dentre outros. Um depoente identificou a presença de risco de natureza ergonômica e relaciona-o ao esforço físico intenso e repetitividade das tarefas.
(...) como a gente fica o dia inteiro de pé, no futuro poderemos ter vários problemas posturais e até mesmo nas pernas (...) tem risco quanto à postura... Como a gente ergue as caixas pode machucar a coluna (...). (E5)

Atividades em que se faz necessária a mesma postura por longos períodos, como a de realizar a tarefa em pé, poderá determinar problemas de saúde. Considerando o exposto, torna-se importante o trabalhador desenvolver estratégias de enfrentamento para que exerça sua atividade com eficácia sem prejudicar sua saúde, assim é necessário que desenvolva atividades de fortalecimento muscular e pausas para alongamentos.

Permanecer por longos períodos em pé, faz com que o peso do corpo exerça uma pressão importante sobre a coluna vertebral, isto faz com que o líquido gelatinoso encontrado no seu interior saia em direção ao centro dos corpos vertebrais, tornando-os menos hidratados e espessos ${ }^{(12)}$. Para que os discos vertebrais voltem à normalidade é necessário um período de repouso significativo. No entanto, a repetição ou a manutenção por tempo prolongado de uma pressão ou a ausência de carga estática nos discos são suficientes para alterarem sua nutrição desencadeando alterações degenerativas ${ }^{(12)}$.

Com o envelhecimento, este mecanismo começa a deteriorar, o que diminui sua elasticidade. Esta pressão repetitiva e frequente sobre os discos, mesmo que não seja intensa, pode ocasionar a aceleração da degeneração discal, levando à perda da sensibilidade e amortecimento ${ }^{(12)}$.

Riscos ergonômicos são elementos físicos e organizacionais que interferem no desempenho da atividade laboral e, por consequência, nas características psicofisiológicas do envolvidos. Este inclui posto de laboral inadequado, ventilação e iluminações fora dos padrões, problemas relacionados com a organização das atividades ocupacionais, dentre outros ${ }^{(11)}$.

Contudo, a educação postural tem a finalidade de possibilitar que a pessoa seja capaz de proteger ativamente seus segmentos móveis de lesões nas condições de vida diária e profissional, seja no plano estático ou dinâmico ${ }^{(12)}$. Assim, a educação postural não tem como objetivo limitar as atividades, mas ao contrário, permitir sua realização dentro de um espaço de segurança gestual.

Diante do exposto, vale lembrar que, atualmente, muitas indústrias implementam formas de adequação dos ambientes laborais com vistas a qualificar as condições em que a atividade é desenvolvida na perspectiva de diminuir acidentes e agravos. No entanto, não é uma realidade unânime. Cabe destacar, a necessidade de o empregador desenvolver estratégias que minimizem os riscos ocupacionais no intuito de proteger ao máximo a saúde e integridade física dos seus servidores e, consequentemente, melhora na qualidade de vida do trabalhador.

\section{B. Medidas de segurança adotadas na perspectiva de mi- nimizar os riscos ocupacionais}

$\mathrm{Na}$ contemporaneidade, por vezes, o homem destina o maior tempo do seu dia à realização de atividades laborais. O ser humano se reconhece, bem como a sociedade, pelo 
trabalho que desenvolve. Neste sentido, a atividade que o indivíduo realiza tem profunda ligação com a autoimagem e autoestima, ou seja, com sua identidade, evidenciando o papel central do trabalho na sua vida ${ }^{(13)}$. Desta forma, o adoecimento tem potencial de ameaçar sua identidade. E, mesmo com dificuldades, os trabalhadores permanecem nas suas práticas profissionais, são impulsionados para atuar, visto que esta é a maneira pela qual dão sentido a existência e integração na sociedade, sendo assim, reconhecidos como seres sociais na sociedade capitalista ${ }^{(14)}$.

Sob o aspecto socioeconômico, a saúde compõe, juntamente com a renda e a educação, o Índice de Desenvolvimento Humano (IDH) dos cidadãos. Estas variáveis permitem avaliar as condições de vida de uma população, inclusive da classe trabalhadora ${ }^{(9)}$.

Para as empresas que contratam colaboradores sob o regime de trabalho da CLT, entre as medidas preventivas de ação coletiva previstas pela legislação trabalhista está a obrigatoriedade de instituir a Comissão Interna de Prevenção de Acidentes (CIPA). A referida comissão deve implementar ações de proteção aos colaboradores com a finalidade de reduzir, significativamente, a presença dos riscos ocupacionais, os acidentes, bem como das doenças ocupacionais e ou relacionadas ao trabalho ${ }^{(7)}$.

Conforme a Portaria 3.214/78 do Ministério do Trabalho e Emprego, a Norma Regulamentadora n 5 institui a CIPA e atribui a ela identificar os riscos do processo de trabalho; desenvolver um plano de atividade que possibilite a ação preventiva na solução de problemas de segurança e saúde; participar na implementação e no controle da qualidade das medidas de prevenção; avaliar prioridades e verificar os ambientes e condições de trabalho; colaborar no desenvolvimento e implementação do Programa de Prevenção de Riscos Ambientais e de outros programas relacionados à segurança e saúde laboral; dentre outras.

Portanto, ações na área da saúde do trabalhador têm como objetivo primordial implementar mudanças nos processos laborais que contemplem, em toda sua dimensão, as relações saúde-trabalho, por meio de uma atuação multiprofissional, interdisciplinar e intersetorial.

Neste sentido, os depoentes pontuaram situações de risco e os métodos de prevenção disponibilizados e, alguns afirmam que receberam treinamentos e orientações no que se refere ao uso correto de equipamentos de proteção individual (EPI) bem como, acerca dos riscos gerados em cada posto.

Pode acontecer de prensar os dedos ou um braço... É muito fácil. Fiz treinamento pela CIPA, treinamento de primeiros socorros, incêndio, e quanto ao uso de produtos tóxicos. (...) mas vejo que ainda falta muita explicação para os funcionários. (E14)

Antes de a gente começar, orientam para amarrar o cabelo e somos informados quanto ao uso de calçado fechado. Também todas as informações de como fazer, de como devemos nos prevenir para que não ocorra acidente. Eles explicam bem, passam as informações e falam sobre os riscos que tem nessa máquina. Passam na fábrica volta e meia para orientar. (E7)

Ao considerar o exposto, torna-se necessário que os cipeiros façam visitas periódicas nos diversos setores da empresa, na perspectiva de identificar comportamentos de risco e, também, reforçar a necessidade do cumprimento das normas de segurança desenvolvidas pela empresa.

Nesse sentido, o papel da CIPA enquanto educadora é fundamental no que tange às ações de proteção à saúde no ambiente de laboral. Quando bem orientados e informados quanto ao uso adequado dos diferentes métodos para prevenção de acidentes, a ocorrência torna-se menos evidente, consequentemente, reflete em qualidade de vida.

Teve uma situação que estavam queimando fio e eu me senti mal, e ai eles me forneceram uma máscara para eu fazer uso isso é uma medida de segurança, pois eu estava inalando essa coisa ruim. (E7)

As ações são estabelecidas por meio de proteção coletiva e individual. Proteção coletiva inclui ações que visam minimizar e proteger uma ou mais pessoas. Já a individual, busca proteger apenas um indivíduo, equipando-o de forma segura por meio do $\mathrm{EPI}^{(7)}$.

Em relação aos EPIs, a Norma Regulamentadora (NR) no 6 da Portaria 3214/78 do MTE estabelece que estes compreendem todo dispositivo ou produto utilizado, individualmente, com o intuito de proteger contra riscos que poderão ameaçar a segurança e a saúde ocupacional, estes equipamentos devem ser usados sempre que as medidas de ordem geral não ofereçam completa proteção contra os riscos de acidentes e danos a saúde ${ }^{(7)}$.

A exposição aos diversos fatores de risco em um processo produtivo está diretamente relacionada às atitudes, ao nível de cuidados para minimização de riscos, à própria natureza do processo produtivo e ao ambiente, seja ambiente laboral e seu entorno ${ }^{(15)}$. Embora a NR n ${ }^{\circ} 6$ determine, aos empregadores, a obrigação de fornecer, gratuitamente, o EPI adequado ao risco, é estritamente necessário que o trabalhador use em todas as atividades, de forma contínua, conforme evidenciado na fala a seguir.

Protetor, creme, luvas. Usados todos os dias dependendo do setor que você trabalha é mais usado. (....) Os lugares que mais temos risco tem que usar sempre (...) tem lugar que não tem tanto risco (...). (E2)

Constata-se que alguns depoentes fazem o uso dos EPIs quando julgam desenvolver atividade de risco, ao invés de fazê-lo, permanentemente. Os riscos, muitas vezes, podem ser banalizados por indivíduos que estão imersos em um mesmo processo ao longo dos anos de atuação profissional, fato que pode ser o causador de agravos ${ }^{(14)}$.

No entanto, este fato não se constitui em regra, pois, quando questionados acerca das medidas de segurança adotadas na perspectiva de minimizar os riscos ocupacionais, por eles 
identificados, alguns depoentes relatam fazer uso contínuo dos dispositivos de segurança, destacando situações em que se faz necessário o uso dos mesmos.

Usado creme, protetores de ouvido. Fazem a gente usar calçado fechado não podemos usar salto pois, se caso um dia pegar fogo, como vamos correr do local? (E3)

Fazer uso de calçado fechado, protetor de orelha, cremes se necessário, cuidar com a postura aqui em meu setor. (E4)

Protetor tem que usar calçado fechado, cabelo atado, pois é isso que eles cobram da gente fazendo isso diminui uma grande quantidade de risco que podem vir a ocorrer. É usado a todo o momento quando estamos em nosso posto de trabalho já temos que estar fazendo uso deles. (E11)

A escolha adequada do EPI favorecerá de forma recíproca os envolvidos, que se sentirão protegidos e alcançarão seus objetivos em relação à prevenção de acidentes. Segundo a Norma Regulamentadora $n^{\circ} 6$ da Portaria 3214\78 do MTE, cabe ao empregador fornecer o EPI apropriado ao risco, bem como instrumentalizá-lo quanto ao uso correto, sua conservação e guarda ${ }^{(7)}$. Também, substituí-lo sempre que se fizer necessário.

Importante salientar, que, por vezes, os problemas relacionados à saúde e à segurança nas pequenas empresas estão mais ligados a dificuldades na gestão de riscos. Desta forma, destaca-se a importância da avaliação permanente dos riscos ambientais e do desenvolvimento de ações em educação em saúde, na medida em que a indústria calçadista constitui-se em um ambiente permeado de riscos e passível de gerar agravos a saúde. Assim é indiscutível a necessidade de atualizar-se constantemente no que se refere aos métodos de prevenção de acidentes e ao comportamento seguro no contexto do trabalho. Estas ações educativas devem envolver múltiplos saberes e fazeres, que envolvem conhecimentos e práticas multiprofissionais ${ }^{(16)}$.

Salienta-se que é de suma importância a construção coletiva de medidas de promoção que valorizem e reconheçam o trabalhador, contribuindo para o sentimento de satisfação e alegria na realização do trabalho ${ }^{(17)}$. Da mesma forma, essas ações coletivas necessitam envolver a equipe gestora da empresa, no intuito de promover espaço laboral seguro, minimizando as situações de estresse inerentes ao ambiente que oferece riscos, bem como preservar a integridade física e emocional dos seus trabalhadores.

\section{CONSIDERAÇÕES FINAIS}

O ambiente de trabalho da indústria calçadista é um espaço com vários riscos e, neste sentido, deve ser objeto de constante avaliação, controle e de desenvolvimento de ações em educação permanente. Ao analisar os relatos dos depoentes percebeu-se que a maioria dos envolvidos tinha uma visão parcial dos riscos inerentes a seu processo de trabalho e as medidas de segurança que deveriam ser implementadas, na perspectiva de reduzir ou mesmo de evitar sua exposição. Foram identificados riscos inerentes ao trabalho, com consequências imediatas, ou seja, situações que interferem na integridade física como amputações e esmagamentos. Também, sucintamente, o ergonômico foi lembrado.

No entanto, destaca-se que o risco químico decorrente do processo de preparo da matéria prima (couro e derivados) envolve manuseio de produtos que podem determinar agravos para a saúde, os quais não foram lembrados pelos entrevistados. Ainda o risco físico manifesto pela exposição ao ruído, foi sinalizado por uma pequena parcela dos sujeitos entrevistados, como a necessidade de uso de protetor auditivo; no entanto, não manifestaram as consequências de dano à saúde, em especial, em longo prazo.

Destaca-se que a instituição pesquisada fornece aos seus colaboradores EPI adequado para as necessidades conforme o posto de trabalho e risco advindo do processo a ser efetivado. Também, observou-se que a reposição dos mesmos era imediata e sem restrição de quantidade.

Outro achado do estudo foi a deficiência de informações por parte de alguns sujeitos, devendo-se salientar a necessidade da realização de treinamentos em segurança do trabalho, conforme preconiza a legislação trabalhista vigente. Também, a manutenção de uma equipe de saúde com vistas a qualificar e ampliar as ações educativas e corretivas no campo da saúde do trabalhador.

Por serem escassos os estudos e publicações voltados para a indústria calçadista e, com vistas aos resultados do estudo, recomendam-se novas investigações, de forma a ampliar o número dos sujeitos e locais de pesquisa, permitindo verificar se a realidade neste tipo de indústria é semelhante e possibilitar propostas de ações buscando a prevenção de acidentes e doenças e a promoção da saúde dos trabalhadores deste setor.

\section{REFERÊNCIAS}

1. Godinho Filho, M, Fernandes FCF, Lima, AD. Pesquisa em gestão da produção na indústria de calçados: revisão, classificação e análise. Gest Prod 2009;16(2):163-186.

2. Franco-Benatti, DM. Acidentes e doenças relacionadas ao trabalho na indústria de calçados de franca-SP. Ribeirão Preto. Dissertação [Mestrado em Ciências] -Faculdade de Medicina de Ribeirão Preto; 2011.
3. Cury Junior $\mathrm{CH}$. Qualidade de vida no trabalho e subjetividades docentes. Evidência 2010;(6):89-110.

4. Borsoi ICF, Rigotto RM, Maciel RH. Da excelência ao lixo: humilhação, assédio moral e sofrimento de trabalhadores em fábricas de calçados no Ceará. Cad Psicol Soc Trab 2009;12(2):173-187.

5. Silva EJ, Lima MG, Marziale MHP. O conceito de risco e 
os seus efeitos simbólicos nos acidentes com instrumentos perfurocortantes. Rev Bras Enferm [periódicos na internet]. 2012 set.out; 65(5): 809-814. Disponível em: http:// dx.doi.org/10.1590/S0034-716720120005000147167.

6. Sêcco IAO, Robazzi MLCC. Acidentes de trabalho na equipe de enfermagem de um hospital de ensino do Paraná - Brasil. CiencEnferm [periódicos na internet]. 2007;13(2):65-78. Disponível em: http://www.scielo.cl/scielo.php?pid=S0717-95 $532007000200008 \&$ script $=$ sci_arttext.

7. Ministério do Trabalho. Normas regulamentadoras: segurança e medicina do trabalho. São Paulo: o Ministério; 2011.

8. Minayo MCS. Pesquisa Social: teoria, método e criatividade. 29 ed. Rio de Janeiro: Vozes; 2011.

9. Santos LRCS. Saúde do trabalhador e qualidade de vida no centro do debate sobre política pública de desenvolvimento regional na Bahia: o caso do ramo calçadista. Rev Saúde Coletiva 2010;7(41):146-51.

10. Silva MKD, Zeitoune RCG. Riscos ocupacionais em um setor de hemodiálise na perspectiva dos trabalhadores da equipe de enfermagem. Esc Anna Nery Rev Enferm 2009;13(2);279-286.

11. Neves HCC, Souza ACS, Medeiros M, Munari DB, Ribeiro LCM, Tipple AFV. Segurança dos trabalhadores de enfermagem e fatores determinantes para adesão aos equipamentos de proteção individual. Rev. Latino-Am Enfermagem 2011;19(2):[08 telas].

12. Braccialli LMP, Vilarta R. Aspectos a serem considerados na elaboração de programas de prevenção e orientação de problemas posturais. Rev Paul Educ Fís 2000;14(2):159-71.

13. Pintor EAS. Sofrimento mental em vendedores na Grande São Paulo: a destituição do ser pela organização do trabaIho. Rev Bras Saúde Ocup 2010;35(122):277-288.

14. Ritter, RS. Análise de variáveis da Síndrome de Burnout em profissionais de enfermagem e médicos de uma unidade de emergência de um hospital geral. ljuí. Monografia [Graduação]-Universidade Regional do Noroeste do Estado do Rio Grande do Sul; 2007.

15. Neves EB. Gerenciamento do risco ocupacional no Exército Brasileiro: aspectos normativos e práticos. Cad Saúde Pública 2007;23(9):2127-2133.

16. Matos E, Pires DEP, Sousa GW. Relações de trabalho em equipes interdisciplinares: contribuições para novas formas de organização do trabalho em saúde. Rev Bras Enferm 2010;63(5):775-81.

17. Becke CLC, Prochnow A, Silva RM, Prestes FC, Tavares JP. Fatores que favorecem e dificultam o trabalho do enfermeiro nos serviços de atenção à saúde. Esc Anna Nery Rev Enferm 2010;14(3):490-95. 